\title{
The Impact of Corporate Social Responsibility on the Performance of Pharmaceutical Companies in Jordan
}

\author{
Dr. Abdelghafour Al-Zawahreh \\ Associate Professor \\ The Hashemite University \\ Jordan \\ Asma R. Mahmoud \\ Master Student, the Hashemite University, Zarqa \\ Jordan \\ Dr. Abdelbaset M. Alkhawaldeh \\ Assistant Professor \\ Jadara University, Irbid \\ Jordan
}

\begin{abstract}
The purpose of this study was to examine the impact of corporate social responsibility (CSR) on the performance of pharmaceutical companies in Jordan. The sample of the study consisted of 492 employees from 14 pharmaceutical companies. Results revealed that there was a positive impact of CSR practices on pharmaceutical company's performance. Results also indicated that customer responsibility dimension had the highest impact on the company's performance, followed by employee, supplier, and community. However, environmental responsibility dimension had the lowest impact on the performance. In light of previous findings, the study suggested a number of recommendations for the field of study.
\end{abstract}

Keywords: corporate social responsibility, company's performance, pharmaceutical companies, and Jordan.

\section{Introduction and Theoretical Framework}

The $21^{\text {st }}$ century encountered many challenges for businesses such as globalization, new markets, customer satisfaction, tough competition and many more. Nowadays, it is important for companies to participate in environmental conservation values and be socially active in the communities in order to be prosperous and keep up economic growth and development (McWilliams \& Siegel, 2001). Sustainable development is linked directly to the adoption of a socially responsible business behavior (Wilkinson, A. Hill, M. \& Gollan, P., 2001). The business share of sustainable development can be referred to as corporate social responsibility (CSR) (Carroll \& Shabana, 2010).

CSR is a concept that has been primarily introduced to the world of business since the 1950's, and it gained special attention in management studies in the 1970's (Friedman, 1970). Adopting and practicing CSR is becoming necessary in developing world because of the considerable environmental, social, and economic problems (Albareda, L., Lozano, M., \& YSA, T., 2007). The concept was flourished and branched into many areas aimed to achieve higher goal of business responsibility towards the community in which it operates along with environment, employees, stakeholders and more (Matten \& Moon, 2008).

The impact of CSR on corporate performance is complicated and unconvincing as it is still questionable in many parts. Company's performance from CSR perspective has become a greater concern for companies all over the world. There has been an increasing interest in determining the extent that might exist of the impact of CSR practices and its future performance (Bhattacharya, C. Korschun, D. \& Sen, S., 2009). While numerous studies have been conducted to find the impact of CSR on company's performance across industries, definitive studies have not been conducted to determine the link within the pharmaceutical industry. 
Jahmani (1996) indicated that CSR in developing countries is still in primary stages. In Jordan, few studies have been conducted in this field as little attention being given to CSR in relation to other concepts (Khasawneh \& Alzawahreh, 2015).For that, it would be better to be able to investigate previous research findings in this field in general and seeks to find out the motivating factors and dimensions that urge Jordanian managements to invest in CSR practices. Examining CSR through company's performance would give a good start point to assess CSR status in pharmaceutical industry. Therefore, this study aimed to investigate certain CSR dimensions (employee, customer, community, supplier, and environment) from the employees' perspective and its impact on the performance of pharmaceutical company's in Jordan.

Many researchers have investigated dimensions of CSR from several different angles; such as employee, customer, community, supplier, and environment responsibilities and adopted the most applicable dimensions in the countries they research. Regarding employee responsibility, it is to be noted that work environment is demanding for more than conventional concepts. The classical notion about employees that their only concern is paycheck has been extended to more claims. They want a sense of appreciation, respect and gratitude from their employer and work place. Bauman \& Skitka (2012) indicated that employees are the key players, and the main stakeholders in the company. Also, the practice of CSR toward employees affects the company performance.

Regarding customer responsibility, it is to be noted that building good customer relations is a priority for any business as customers are the key player for company profit, durability over years and stability in the market. It is crucial for any company to focus on customer satisfaction, engagement and trust if it is looking for long-term success (Chung, K. Yu, J. Choi, M. \& Shin, J., 2015).

As for community responsibility, constructing strong communications and mutually beneficial relationships with local community is a key success for any corporation. Community plays the main role in every corporate founded within its region and hence enhance corporation performance and strengthens its status. On the other hand, corporate could help improving society and community by contributing in many activities and local projects for specific purposes like: hiring employees form the same community, education scholarships, giving specialized training to cover certain community needs, providing health care, doing charity, making donations and fund raising (Asatryan, 2012).

In regard to supplier responsibility, requiring connections and interactions with suppliers, occupies a dynamic part in CSR approaches used at work environment. Suppliers are also well-known these days as supply chain is a valuable concept in corporate business strategy as relations to suppliers organized through supply chain management. Adding CSR values and concepts to those supply chain are believed to have a positive impact on the relation between CSR and supplier (Andersen \& Skjoett-Larsen, 2009).

As for environmental responsibility, governments have depended on legislations and regulations to protect local environment from corporations' exploitations and misuses of natural resources. But the challenge to enforce corporations to bend to rules had been a big concern to governments. So the need to have an approach whereby corporate can implant environmental issues in its business conduct became a necessity. CSR appeared to be the most suitable solution for this issue (Flammer, 2011; Sotamenou, 2014).

Regarding CSR and performance, focusing on performance through many areas is important, particularly for ensuring the success of a business, making company stronger as a whole, to be able to perform better in the market and to increase its profits. According to literature review, the impact of CSR and corporate performance is still not fully covered by researchers, as they encountered difficulties in measuring the impact of CSR on corporate performance (Maignan \& Ferrell, 2004;Mohammad, A. Altarifi, S. \& Alafi, K., 2014; Montiel 2008; Rasoulzadeh, H. Hosseinipour, S.Yusof, N. Soltani, N.\&Hashemi, S., 2013).

\section{Statement of the Problem}

As the Pharmaceutical industry in Jordan keeps growing, criticism for company's performance increased. So, the need to control and decrease the side effects of these criticisms, which than pushed the industry leaders to follow CSR pathis becoming an urgent issue. To the researcher best knowledge, limited research existed in Jordan. Therefore, the primary purpose of this study was to determine the impact of CSR on the performance of pharmaceutical companies in Jordan.

\section{Study Objectives}

The study aimed to accomplish the following objectives: 
- To describe the level of CSR practices in pharmaceutical companies in Jordan.

- To identify the level of the perceived organizational performance in pharmaceutical companies in Jordan.

- To determine the impact of CSR practices on the perceived performance of pharmaceutical companies in Jordan.

\section{Significance of the Study}

The results of this study are important for a number of reasons. First, the outcomes of this study may helpin directing the attention of decision makers in manufacturing companies in Jordan to the practice of CSR and how might affect their organizational performance. The result of this study will also help fill in the gap in the literature related to the lack of research being conducted in Jordan industry related to the impact of CSR on company's performance.

\section{Research Methods and Procedures}

\section{Research Design}

This study is quantitative in nature. It was conducted using a survey methodology. Means, standard deviation, frequencies, percentages, multiple regression analysis were employed in this study. Means and standard deviations were used to determine the attitudes of the respondents toward CSR activities level and towards the level of perceived performance. Multiple regression analysis was used to examine the impact of CSR on the performance of studied companies.

\section{Population and Sample}

The population for this study was composed of all the pharmaceutical companies in Jordan (14 companies) that were registered in the Jordanian Association of Pharmaceutical Manufacturers (JAPM). The number of studied companies was (14), with approximate number of (5.550) working employees. The sample of the study based on four managerial levels of employees from managers, assistant managers, head of sections and supervisors. A sample size of (10\%) was randomly chosen from each pharmaceutical company. (550) questionnaire was distributed to the selected respondents and only (492) usable questionnaires were used for statistical analysis.

\section{Instrument}

A questionnaire was used as a main instrument in this study. A self-administered technique was utilized to collect data. The questionnaire was consisted of three parts. The first part of the questionnaire was to collect information about demographic and functional characteristics of participants including gender, age, job title, educational level, and years of experience. The second part was about gathering information based on the assessment of participants towards CSR dimensions (Employee, Customer, Community, Supplier and Environment). The third part was defined indicators to measure pharmaceutical company's performance. The questions of the questionnaire were relies on the instrument that developed by (Bayoud, 2012; Stancu, 2011; Sweeney, 2007), with modifications. The questionnaire was consisted of 38 items (26 items measuring participants attitudes toward CSR, 12 items measuring companies performance) that uses a five-point Likert scale ranged as follows: Strongly Agree $=5$, Agree $=4$, Nutral $=3$, Disagree=2, Strongly Disagree $=1$. To test the validity of the questionnaire and to assure clarity and for removing ambiguity, a review and judging have been made to the questionnaire by academics from different Jordanian universities and from managers working in pharmaceutical companies. All the modifications and notes were considered in the final version of the questionnaire. To test questionnaire reliability, Cranach's Alpha coefficient was used for each of the dimensions in the questionnaire and the results were as follows: All CSR dimensions (0.96), employees (0.91), customers (0.75), community (0.84), suppliers (0.85), environment (0.92), and company's performance (0.95). It is to be noted that all the previous scales show satisfied value of reliability.

\section{Data Collection}

In this study, the researcher contacted each participant that participated in the study and asked for permission to conduct the study. Once permission was obtained, the researcher visited each targeted company, explained to employees the nature and purpose of the study. The participants were also insured confidentiality, voluntaries, and anonymity. After completion, respondents returned the completed questionnaires to the researcher in attendance. The questionnaire took approximately 15 minutes to complete. The data collection process was achieved in September 2016. 


\section{Results}

\section{Demographic Analysis}

Five demographic elements were included in this study (gender, age, job title, educational level, and years of experience). Employee gender showed that male employees were (60.2\%) while female employees were (39.8\%). Employee Age with the period from (30) to less than (40) was the highest ratio with (48\%) while the lowest was for age period (50) and more with ratio (10.6\%). Employee job title revealed that head of section was the highest ratio of $(31.7 \%)$ and assistant manager was lowest ratio with (14.6\%). Employee educational level was (65.9\%) for B.Sc. degree and (1.6\%) for diploma and less. As for employee years of experience, the highest ratio was for years of experience from (5) to less than (10) with ratio (46.3\%) and the lowest was for years from (15) to less than (20) with ratio $(13.8 \%)$.

Table 1 shows the scale that used to rate the mean of sample respondent's answers. It is calculated using the weighted average method (Weighted Mean) for the five options and values: 5, 4, 3, 2 and 1 scale.

\section{Table 1: The scale that used to rate the mean of sample respondent's answers}

\begin{tabular}{|l|l|}
\hline Mean & Level \\
\hline Less than 1.80 & V. Low \\
\hline From 1.80 to less than 2.60 & Low \\
\hline From 2.60 to less than 3.40 & Moderate \\
\hline From 3.40 to less than 4.20 & High \\
\hline From 4.20 and more & V. High \\
\hline
\end{tabular}

\section{Objective 1}

Objective 1 was to determine the level of CSR practices among pharmaceutical companies in Jordan. Descriptive statistics including means and standard deviations were used to achieve this objective. Table 2presents descriptive analysis of the respondents characteristics that will help prepare for a better understanding of advanced analysis in this study.

Table 2: Means and standard deviations for all dimensions of CSR

\begin{tabular}{|l|l|l|l|}
\hline CSR Dimension & Mean & SD & Level \\
\hline Employee Responsibility & 3.80 & 0.664 & High \\
\hline Customer Responsibility & 3.46 & 0.898 & High \\
\hline Community Responsibility & 3.54 & 0.651 & High \\
\hline Supplier Responsibility & 3.45 & 0.724 & High \\
\hline Environment Responsibility & 3.10 & 0.669 & Moderate \\
\hline Total & $\mathbf{3 . 5 1}$ & $\mathbf{0 . 5 7 4}$ & High \\
\hline
\end{tabular}

Table 2clarified that, employees dimension had the highest mean value (3.80), followed by community dimension with a mean of (3.54). However, the environmental dimension had the lowest mean value of (3.10).

\section{Objective 2}

Objective 2 was to determine the level of the perceived performance in pharmaceutical companies in Jordan. Table 3 showed means and standard deviations of respondents' answers for performance indicators.

Table 3: Means and standard deviations for performance indicators

\begin{tabular}{|l|l|l|l|}
\hline CSR Dimension & Mean & SD & Level \\
\hline Reputation & 4.73 & 0.424 & Very High \\
\hline Profit & 4.15 & 0.613 & High \\
\hline Customer Satisfaction & 4.00 & 0.628 & High \\
\hline Market Share & 3.27 & 0.734 & Moderate \\
\hline Total & 4.04 & 0.465 & High \\
\hline
\end{tabular}

Table 3 showed that reputation had the highest mean value of (4.73), while the market share had the lowest mean value of (3.27). 


\section{Objective 3}

Objective 3 was to determine the impact of the all components of CSR Practices on the pharmaceutical companies' performance. This objective was accomplished utilizing multiple regression analysis. As shown in table 4 . The result of multiple regression analysis indicated that the independent variables explained $52.9 \%$ of the common variance in the dependent variable.

As shown in Table 4, customer responsibility was the highest impact variable, explaining $23 \%$ of the variance in performance. The second dimension was employee responsibility, explaining $18.4 \%$ of the variance. The third dimension was supplier responsibility, explaining $18.2 \%$ of the variance. The fourth dimension was community responsibility, explaining $17.2 \%$ of the variance. The lowest impact dimension was environmental responsibility, explaining $12 \%$ of the variance.

Table 4: Multiple regression analysis of CSR on company's performance

\begin{tabular}{|c|c|c|c|c|c|c|c|}
\hline Variable & $\mathbf{R}$ & $\mathbf{R}^{2}$ & $\mathbf{F}$ & Sig. F & Beta & $\mathbf{T}$ & Sig. T \\
\hline Supplier & \multirow{5}{*}{0.727} & \multirow{5}{*}{0.529} & \multirow{5}{*}{109.33} & \multirow{5}{*}{0.000} & 0.182 & 3.864 & 0.000 \\
\hline Environment & & & & & 0.120 & 2.919 & 0.004 \\
\hline Employee & & & & & 0.184 & 3.905 & 0.000 \\
\hline Customer & & & & & 0.230 & 5.349 & 0.000 \\
\hline Community & & & & & 0.172 & 3.602 & 0.001 \\
\hline
\end{tabular}

\section{Discussion}

Based on the respondent's perception, the findings of this study indicated that the pharmaceutical companies in Jordan overall had high levels of CSR practices. Furthermore, findings indicated that the level of perceived performance had high level overall among the studied companies. The findings also indicated that there was a positive impact of CSR five dimensions (employee responsibility, customer responsibility, community responsibility, supplier responsibility, and environmental responsibility) on the perceived companies' performance, and this result was consistent with previous research (Rasoulzadeh et al., 2013; Rettab, B. Brik, A. \& Mellahi, K.).

Research results showed that customer responsibility dimension had the highest impact of all dimensions which indicated that pharmaceutical companies care most about their customers, contentment and wellbeing to improve company performance and have a big advance towards healthier way of business development. This result was consistent with the previous research (Asatryan, 2012; Chung et al.,2015). The findings of the study showed that employee dimension was the second variable that is very important to improve company performance. This result was consistent with the previous studies (Bauman \& Skitka, 2012;Gond, J. El-Akremi, A. Igalens, J. \&Swaen, V., 2010; Iqbal, N. Ahmad, N. Sheeraz, M. \& Bashir, N., 2012).The findings of the study also showed that supplier was the third dimension to focus on when companies practices CSR, which indicated that supplier also important to improve company performance. The result was consistent with previous research (Mushanyuri, 2013; Munasinghe \& Malkumari, 2012; Tilakasiri, 2013; Cruz,2009). The current study results indicated that community is ranked before the last dimension of company's concentration in practicing CSR activities to improve their performance. This result is relative to the extent company awareness of the role of community as a way to get much higher performance. This result was supported by previous studies (Ismail, 2009; Mushanyuri, 2013;Munasinghe \& Malkumari, 2012; Tilakasiri, 2012). Research result showed that environment came in the last interest of companies when practicing CSR to improve performance. Companies need to focus more on this dimension in the future. Nevertheless, this dimension was positively impacted company' performance. This result was consistent with the previous research (Mishra \& Suar, 2010).

\section{Recommendations and Future Research Directions}

Based on the findings of this study, it is recommended that organizations should establish special department for CSR that has own budget as a part of the organization general budget. This department should have employees with real experience in CSR in order to improve their performance. Organizations need more coordination and cooperation between them, when implementing CSR activities, especially for local community and environment to get the best results. Organizations should pay more attention to practicing CSR on customers, as they will improve company performance. 
Media campaigns should be held, to foster CSR culture, spread knowledge of CSR concepts, and encourage companies to carry out research studies regarding CSR practices in their workplaces. Regulations and laws concerning practicing CSR must be defined by responsible entities. Facilitations and tax reductions should be given to companies practicing CSR in order to encourage them to go forward in this field. This study suggests several implications for future researches to be done in this field. Further studies need to be undertaken in Jordan that correlate CSR dimensions with other variables such as innovation, competitive advantage and job satisfaction. As it is the current trend in business that improve company's performance, research studies of CSR in small and medium sized enterprises are very important as they construct $95 \%$ of Jordanian economy. It is hoped that this study will encourage other companies in Jordan to invest more in CSR and its practice.

\section{References}

Albareda, L., Lozano, M.,\& YSA, T. (2007). Public policies on corporate social responsibility: The role of governments in Europe. Journal of Business Ethics, 74 (4), 391-407.

Andersen, M., \& Skjoett-Larsen, T. (2009).Corporate social responsibility in global supply chains.Supply Chain Management: An International Journal, 14 (2), 75-86.

Asatryan, R. (2012).The effect of CSR initiatives on customer loyalty in the airline industry. Master Thesis, Department of Economics, Tomas Bata University.

Bauman, C. \&Skitka, L. (2012).Corporate social responsibility as a source of employee satisfaction. Research in Organizational Behavior, 32 (1), 63-86.

Bayoud, N. (2012).Corporate social responsibility disclosure and organizational performance: The case of Libya, a mixed methods study.PhD Dissertation, Faculty of Business and Law, University of Southern Queensland, Australia.

Bhattacharya, C. Korschun, D. \& Sen, S. (2009).Strengthening stakeholder-company relationships through mutually beneficial corporate social responsibility initiatives.Journal of Business Ethics, 85 (2), 257-272.

Carroll, A. \& Shabana, K. (2010).The business case for corporate social responsibility: A review of concepts, research and practice. International Journal of Management Reviews, 12 (1), 85-105.

Chung, K. Yu, J. Choi, M. \& Shin, J. (2015).The effects of CSR on customer satisfaction and loyalty in china: The moderating role of corporate image".Journal of Economics, Business and Management, 3 (5), 542547.

Cruz, J. (2009). The impact of corporate social responsibility in supply chain management: Multi criteria decision-making approach. Decision Support Systems, 48 (1), 224-236.

Flammer, C. (2011). Corporate social responsibility and shareholder reaction: The environmental awareness of investors. Academy of Management Journal, 56 (3), 758-781.

Friedman, M. (1970). The social responsibility of business is to increase its profits.The New York Times magazine, 33, 122-126.

Gond, J. El-Akremi, A. Igalens, J. \&Swaen, V.(2010).Corporate social responsibility influence on employees.International Centre for Corporate Social Responsibility, 54 (1), 1479-5124.

Iqbal, N. Ahmad, N. Sheeraz, M. \&Bashir, N.(2012).The impact of perceived corporate social responsibility (CSR) on job attitude and performance of internal stakeholders.International Journal of Human Resource Studies, 2 (4), 77-86.

Ismail, M. (2009).Corporate social responsibility and its role in community development: An international perspective.The Journal of international Social Research, 2 (9), 199-209.

Jahmani, Y. (1996).Social responsibility accounting and public shareholding companies in Jordan.Abhath AlYarmouk, 12, 45-85.

Khasawneh, S. \& Al-Zawahreh, A. (2015).Future business leaders and corporate social responsibility in Jordan: A sustainable competitive approach in the 21st century.International Journal of Management Practice, 8 (2), 137-151.

Maignan, I. \& Ferrell, O. (2004). Corporate social responsibility and marketing: An integerative framework.Journal of the Academy of Marketing Science, 32 (1), 3-19.

Matten, D. \& Moon, J. (2008). Implicit and explicit CSR: A conceptual framework for a comparative understanding of corporate social responsibility. Academy of Management Review, 33 (2), 404-424. 
McWilliams, A. \& Siegel, D. (2001). Corporate social responsibility: A theory of the firm perspective.The Academy of Management Review, 26 (1), 117-127.

Mishra, S. \&Suar, D. (2010). Does corporate social responsibility influence firm performance of Indian companies? Journal of Business Ethics, 95 (4), 571-601.

Mohammad, A. Altarifi, S. \&Alafi, K. (2014).The impact of corporate social responsibility toward employees on company performance: AJordanian study.Interdisciplinary Journal of Contemporary Research in Business, 6 (5), 255-270.

Montiel, I. (2008).Corporate social responsibility and corporate sustainability separate pasts,common futures.Organization and Environment, 21 (3), 245-269.

Munasinghe, M. \&Malkumari, A. (2012).Corporate social responsibility in small and medium enterprises (SME) in Sri Lanka.Journal of Emerging Trends in Educational Research and Policy Studies, 3 (2), 168-172.

Mushanyuri, B. (2013). The impact of corporate social responsibility on sustainable supply chains: A review of literature.European Journal of Business and Social Sciences, 1 (10), 52-60.

Rasoulzadeh, H. Hosseinipour, S.Yusof, N. Soltani, N.\&Hashemi, S. (2013).Effect of dimensions of corporate social responsibility on organization performance. International Journal of Innovative Ideas, 13 (2), 37 47.

Rettab, B. Brik, A. \&Mellahi, K. (2009). A study of management perceptions of the impact of corporate social responsibility on organizational performance in emerging economic: A case of Dubai.Journal of Business Ethics, 89 (3), 371-390.

Stancu, A. (2011).The role of corporate social responsibility in building employer's brand.Transformations in Business and Economics, 10 (2), 741-753.

Sotamenou, J. (2014).Corporate social responsibility amount small and medium size enterprises in Cameroon. Journal of Entrepreneurship and innovation Management, 3 (2), 1-19.

Sweeney, L. (2007). Corporate social responsibility in Ireland: Barriers and opportunities experienced by SMEs when undertaking CSR. Corporate Governance, 7 (4), 516-523.

Tilakasiri, K. (2013).Corporate social responsibility and social, economic and environmental development in Sri Lanka. Kelaniya Journal of Human Resource Management, 8 (2), 93-133.

Wilkinson, A. Hill, M. \& Gollan, P. (2001).The sustainability debate. International Journal of Operations and Production Management, 21 (2), 1492-1502. 